\title{
MINIREVIEW
}

\section{Recent insights into the role of NF-KB in ovarian carcinogenesis}

Ayesha B Alvero*

\begin{abstract}
The NF-KBs are a family of ubiquitously expressed transcription factors that have been described to be responsible for the establishment of an inflammatory response. Studies in the past decade have also demonstrated this family's role in the initiation and progression of hematological and solid tumors. Recently, research has uncovered a specific role for $\mathrm{NF}-\mathrm{kBs}$ in the development and maintenance of ovarian cancer.
\end{abstract}

\section{Clinical overview of epithelial ovarian cancer}

Epithelial ovarian cancer (EOC) accounts for the majority of ovarian cancer and is the most lethal of all gynecological malignancies. It was expected that 21,550 new cases of EOC would be diagnosed in the US in 2009 and that 14,600 women would die from the disease [1]. Although ovarian cancer accounts for only 3\% of all female cancers, it is the fifth most common cause of cancer deaths in women. Given that EOC usually presents with non-specific symptoms, such as bloating or abdominal discomfort, which can all be mistaken for a more benign condition, and because there is currently no means for early detection, patients with EOC are often diagnosed with late-stage disease (International Federation of Gynecology and Obstetrics (FIGO) stage III or IV). On initial diagnosis, patients undergo complete surgical debulking (resection whose only goal is to make subsequent therapy more effective) followed by combination chemotherapy usually consisting of carboplatin and paclitaxel. Approximately $80 \%$ of patients respond to this treatment regimen, which has been the standard for more than 10 years [2]. However, 60 to $80 \%$ of the responders present with recurrent disease between 6 months and 2 years after treatment. Unfortunately, disease

*Correspondence: ayesha.alvero@yale.edu

Department of Obstetrics, Gynecology, and Reproductive Sciences, Yale University School of Medicine, 333 Cedar St, New Haven, CT 06510, USA recurrence is characterized by chemoresistance, resulting in disease progression and death. As a result, the 5-year survival rate for patients diagnosed with late-stage disease is only 15 to $20 \%$ [3].

\section{NF-KB in ovarian cancer initiation and progression}

Chronic inflammation has been associated with tumor initiation and progression. In the ovary, carcinogenesis has been linked to inflammatory processes, such as repeated ovulation, endometriosis and pelvic infections $[4,5]$. The molecular link between inflammation and cancer is nuclear factor $\mathrm{k}$ light chain enhancer of activated B cells (NF- $\kappa B$ ) [6]. The NF- $\kappa B$ family of proteins, which has five members (Table 1), controls several key processes that are required for tumor development and progression, such as: activation of anti-apoptotic genes and genes involved in the progression of cell cycle $[7,8]$; secretion of factors such as tumor necrosis factor (TNF) $\alpha$ and interleukin (IL)-6, which enhances cell growth [6]; promotion of a pro-angiogenic environment through enhanced production of IL-8 and vascular endothelial growth factor [9]; and creation of a microenvironment that may prevent immune surveillance [10] (Figure 1).

A correlation between NF- $\mathrm{KB}$ activation and EOC clinical profile has been described. Guo et al. [11] demonstrated that the expression of NF-kB p65 in EOC tumors is mainly nuclear and that the levels correlate with poor differentiation and late FIGO stage. Moreover, they showed that patients who were positive for NF-KB p65 subunit staining had lower cumulative survival rates and lower median survival (20\% and 24 months, respectively) than patients that were negative $(46.2 \%$ and 39 months, respectively). The correlation between NF-kB activation status (that is, levels of NF-kB p65 and RelB) and poor clinical outcome in EOC patients was corroborated in more recent studies by two other independent groups [12,13].

In addition to these correlation studies [11-13], the in vitro activation or specific inhibition of the NF- $\mathrm{KB}$ pathway using either small-molecule inhibitors or short interfering RNA (siRNA) was recently shown to affect the growth behavior of EOC cells. Using the ligand TNF-like weak inducer of apoptosis (TWEAK) to activate NF-кB 
Table 1. Members of the NF-kB family of proteins

\begin{tabular}{ll}
\hline Member & Other names \\
\hline NFkB1 & NFkB, p105, p50, p50/p105 \\
NFkB2 & p52 \\
NFkB3 & RelA, p65 \\
RelB & \\
C-Rel & \\
\hline
\end{tabular}

in the highly metastatic human EOC cell line HO8910PM, Dai et al. [14] showed that although TWEAKinduced nuclear translocation of NF-kB p65 does not enhance cell growth, treatment with TWEAK for 6 hours can significantly enhance adhesion and promote the migration and invasion capacity of these cells [14]. These effects were inhibited when cells were treated with TWEAK in the presence of the NF- $\mathrm{kB}$ inhibitor pyrrolidine dithiocarbamate.

In another study, which showed that microRNA-9 (miR-9) could control the levels of NF-kB1, the authors [15] showed that a decrease in NF- $\mathrm{kB} 1$ levels, as a result of overexpressing miR- 9 or by using the siRNA expres-

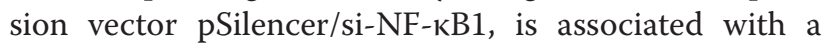
reduction in cell growth and colony formation by the human EOC line ES-2.

In a more recent study using several EOC cell lines, Hernandez et al. [16] showed that inhibition of the NF$\kappa B$ pathway through specific inhibition of inhibitor of NF- $\kappa B$ kinase $\beta$ (IKK $\beta)$ can decrease the percentage of viable CAOV3, IGROV1 and A2780 cells. In addition, they showed that blocking IKK $\beta$ activity through either small-molecule inhibition or siRNA can inhibit anchorage-independent growth and the capacity of the cells to invade through a basement membrane. More importantly, the authors [16] identified the network of genes controlled by the IKK $\beta-N F-\kappa B$ pathway in CAOV3 cells. Using the highly specific IKK $\beta$ small-molecule inhibitor ML120b or IKK $\beta$ siRNA to decrease IKK $\beta$ expression, gene expression microarray results showed that the IKK $\beta$-NF- $\mathrm{kB}$ pathway controls genes associated with EOC cell proliferation, adhesion, invasion, angiogenesis and the creation of a pro-inflammatory microenvironment.

\section{NF-KB signaling and ovarian cancer stem cells}

Our group has identified a subpopulation of EOC cells that is responsive to the pathway involving Toll-like receptor 4 (TLR4) and NF-KB [17]. Treatment with the chemotherapy agent paclitaxel, which is a known TLR4 ligand, induced NF- $\mathrm{KB}$ activation, leading to enhanced cell proliferation. NF- $\mathrm{kB}$ is constitutively active in these cells, resulting in constitutive secretion of pro-inflammatory cytokines [17], and this is brought about by constitutive IKK $\beta$ activity [18]. These cells also express

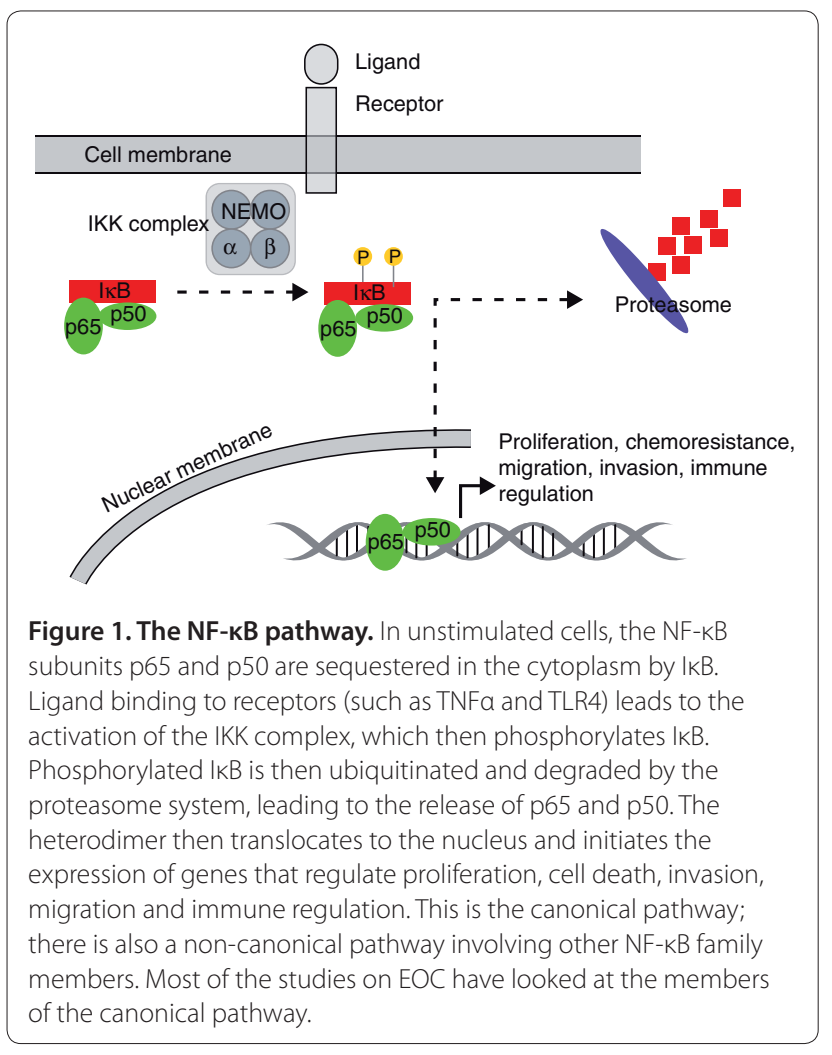

the cancer stem cell marker CD44 and are in fact the ovarian cancer stem cells (OCSCs) [19].

The CD44+ OCSCs are resistant to chemotherapeutic agents, and this resistance is partly regulated by the NF- $\kappa B$ pathway [19]. In our most recent study [20], we showed that the NF-kB inhibitor Eriocalyxin B can sensitize these cells to TNF $\alpha$ - and Fas-mediated apoptosis. The CD44+ OCSCs can also serve as tumor vascular progenitors in vitro and in vivo, an effect also regulated by the NF-kB pathway [21].

\section{Conclusions}

Research in the past 5 years has unraveled the multiple mechanisms that enable NF- $\mathrm{KB}$ to support ovarian carcinogenesis, including that this pathway confers some of the properties of OCSCs. These findings highlight the clinical potential for NF- $\mathrm{kB}$ inhibitors to prevent recurrence and improve survival in EOC patients. The fact that the main effectors of this pathway significantly correlate with disease activity suggests the feasibility of choosing patients that may benefit from targeting this molecular pathway.

\section{Abbreviations}

EOC, epithelial ovarian cancer cells; IKKa, inhibitor of NF-KB kinase a; IKK $\beta$, inhibitor of NF-kB kinase $\beta$; IKB, inhibitor of NFkB; IL, interleukin; NF-kB, Nuclear factor kappa-light-chain-enhancer of activated B cells; OCSC, ovarian cancer stem cells; shRNA, short hairpin RNA; siRNA, small interfering RNA; TNFa, tumor necrosis factor $a$. 


\section{Competing interests}

The author declares that she has no competing interests.

Published: 25 August 2010

\section{References}

1. Jemal A, Siegel R, Ward E, Hao Y, Xu J, Thun MJ: Cancer statistics, 2009. CA Cancer J Clin 2009, 59:225-249.

2. Covens $A$, Carey M, Bryson P, Verma S, Fung Kee Fung M, Johnston M: Systematic review of first-line chemotherapy for newly diagnosed postoperative patients with stage II, III, or IV epithelial ovarian cancer. Gynecol Oncol 2002, 85:71-80.

3. Schwartz PE: Current diagnosis and treatment modalities for ovarian cancer. Cancer Treat Res 2002, 107:99-118.

4. Cramer DW, Welch WR: Determinants of ovarian cancer risk. II. Inferences regarding pathogenesis. J Natl Cancer Inst 1983, 71:717-721.

5. Mandai M, Yamaguchi K, Matsumura N, Baba T, Konishi I: Ovarian cancer in endometriosis: molecular biology, pathology, and clinical management. Int J Clin Oncol 2009, 14:383-391.

6. Karin M: Nuclear factor-kappaB in cancer development and progression. Nature 2006, 441:431-436.

7. Karin M, Lin A: NF-kappaB at the crossroads of life and death. Nat Immunol 2002, 3:221-227.

8. Joyce D, Albanese C, Steer J, Fu M, Bouzahzah B, Pestell RG: NF-kappaB and cell-cycle regulation: the cyclin connection. Cytokine Growth Factor Rev 2001, 12:73-90.

9. Huang S, Robinson JB, Deguzman A, Bucana CD, Fidler IJ: Blockade of nuclear factor-kappaB signaling inhibits angiogenesis and tumorigenicity of human ovarian cancer cells by suppressing expression of vascular endothelial growth factor and interleukin 8. Cancer Res 2000, 60:5334-5339.

10. Karin M, Greten FR: NF-kappaB: linking inflammation and immunity to cancer development and progression. Nat Rev Immunol 2005, 5:749-759.

11. Guo RX, Qiao YH, Zhou Y, Li LX, Shi HR, Chen KS: Increased staining for phosphorylated AKT and nuclear factor-kappaB p65 and their relationship with prognosis in epithelial ovarian cancer. Pathol Int 2008, 58:749-756.

12. Annunziata CM, Stavnes HT, Kleinberg L, Berner A, Hernandez LF, Birrer MJ Steinberg SM, Davidson B, Kohn EC: Nuclear factor kappaB transcription factors are coexpressed and convey a poor outcome in ovarian cancer. Cancer 2010, 116:3276-3284.
13. Darb-Esfahani S, Sinn BV, Weichert W, Budczies J, Lehmann A, Noske A Buckendahl AC, Muller BM, Sehouli J, Koensgen D, Gyorffy B, Dietel M, Denkert C: Expression of classical NF-kappaB pathway effectors in human ovarian carcinoma. Histopathology 2010, 56:727-739.

14. Dai L, Gu L, Ding C, Qiu L, Di W: TWEAK promotes ovarian cancer cell metastasis via NF-kappaB pathway activation and VEGF expression. Cancer Lett 2009, 283:159-167.

15. Guo LM, Pu Y, Han Z, LiU T, Li YX, Liu M, Li X, Tang H: MicroRNA-9 inhibits ovarian cancer cell growth through regulation of NF-kappaB1. FEBS J 2009, 276:5537-5546.

16. Hernandez L, Hsu SC, Davidson B, Birrer MJ, Kohn EC, Annunziata CM: Activation of NF-kappaB signaling by inhibitor of NF-kappaB kinase beta increases aggressiveness of ovarian cancer. Cancer Res 2010, 70:4005-4014.

17. Kelly MG, Alvero AB, Chen R, Silasi DA, Abrahams VM, Chan S, Visintin I, Rutherford T, Mor G: TLR-4 signaling promotes tumor growth and paclitaxel chemoresistance in ovarian cancer. Cancer Res 2006, 66:3859-3868.

18. Chen R, Alvero AB, Silasi DA, Kelly MG, Fest S, Visintin I, Leiser A, Schwartz PE, Rutherford T, Mor G: Regulation of IKKbeta by miR-199a affects NF-kappaB activity in ovarian cancer cells. Oncogene 2008, 27:4712-4723.

19. Alvero AB, Chen R, Fu HH, Montagna M, Schwartz PE, Rutherford T, Silasi DA, Steffensen KD, Waldstrom M, Visintin I, Mor G: Molecular phenotyping of human ovarian cancer stem cells unravels the mechanisms for repair and chemoresistance. Cell Cycle 2009, 8:158-166.

20. Leiser A, Alvero AB, Fu H, Holmberg J, Cheng YC, Silasi D, Rutherford, R, Mor G: Regulation of inflammation by the NFKB pathway in the ovarian cancer stem cells. Am J Reprod Immuno/ 2010, in press.

21. Alvero AB, Fu HH, Holmberg J, Visintin I, Mor L, Marquina CC, Oidtman J, Silas DA, Mor G: Stem-like ovarian cancer cells can serve as tumor vascular progenitors. Stem Cells 2009, 27:2405-2413.

doi:10.1186/gm177

Cite this article as: Alvero AB: Recent insights into the role of NF-KB in ovarian carcinogenesis. Genome Medicine 2010, 2:56. 